Check for updates

Cite this: RSC Adv., 2017, 7, 40401

Received 1st July 2017

Accepted 10th August 2017

DOI: $10.1039 / c 7 r a 07269 d$

rsc.li/rsc-advances

\section{Taking advantage of CTAB micelles for the simultaneous electrochemical quantification of diclofenac and acetaminophen in aqueous media $\uparrow$}

\author{
D. S. Guzmán-Hernández, ${ }^{a}$ M. M. Cid-Cerón, ${ }^{b}$ M. Romero-Romo, (D) c M. T. Ramírez- \\ Silva, (D) ${ }^{\star b}$ M. E. Páez-Hernández, (D) ${ }^{\text {d }}$ S. Corona-Avendaño ${ }^{c}$ and M. Palomar- \\ Pardavé (iD) *c
}

From spectrophotometric and electrochemical techniques, it was shown that cetyltrimethylammonium bromide, CTAB, hemimicelles, formed on the surfaces of a carbon paste electrode (CPE), selectively adsorbed diclofenac, DCF, molecules from a neutral aqueous solution of DCF and acetaminophen, ACT. This CTAB-DCF interaction is so important that it modified the DCF electrochemical oxidation mechanism from a mass-transferred controlled one (in the absence of CTAB) to an adsorption controlled mechanism which allows the simultaneous quantification of both drugs. This novel methodology was used for the individual and simultaneous quantification of DCF and ACT in both aqueous media and synthetic urine. Moreover, it is shown that the analytical method proposed in this work is similar or even better than other more sophisticated and expensive techniques available.

\section{Introduction}

Anionic, cationic or neutral surfactant molecules have the ability to spontaneously form molecular aggregates termed micelles when they are dissolved in water, depending on the ions present and their concentration in solution. ${ }^{1}$ This way, the surfactants have been used to increase the solubility, improve the bioavailability or to prolong the release of various drugs, the stability of analytes associated with exposure under ambient light and normal laboratory atmospheric conditions, or of different types of organic molecules. ${ }^{2-5}$ Surfactants have also been used as masking agents for the simultaneous determination of neurotransmitters ${ }^{6}$ and to promote the percutaneous absorption of some analgesics. ${ }^{7}$ Two of the most important non-steroidal anti-inflammatory drugs (NSAIDS) are diclofenac (DCF), (2-[(2,6-dichlorophenyl) amino]phenyl acetate), and acetaminophen (ACT) commonly known as paracetamol ( $N$-acetyl- $p$-amino-phenol), due to their analgesic, antipyretic and anti-inflammatory properties.

${ }^{a}$ CONACYT-Universidad Autónoma Metropolitana-Iztapalapa, Departamento de Química, Av. San Rafael Atlixco \#186, Col. Vicentina, CDMX, C.P. 09340, Mexico

${ }^{b}$ Universidad Autónoma Metropolitana-Iztapalapa, Departamento de Química, Av. San Rafael Atlixco \#186, Col. Vicentina, CDMX, C.P. 09340, Mexico. E-mail: mtrs218@ xanum.uam.mx

'Universidad Autónoma Metropolitana-Azcapotzalco, Departamento de Materiales, Av. San Pablo \#180, Col. Reynosa-Tamaulipas, CDMX, C.P. 02200, Mexico. E-mail: mepp@correo.azc.uam.mx

${ }^{d}$ Universidad Autónoma del Estado de Hidalgo, Área académica de Química, Carr. Pachuca-Tulancingo Km 45 Mineral de la Reforma, Hidalgo, C.P. 42184, Mexico

$\dagger$ Electronic supplementary information (ESI) available. See DOI: 10.1039/c7ra07269d
Sophisticated analytical methods have been developed for their individual quantification, such as those involving HPLC techniques with UV detector, ${ }^{8}$ diffuse reflectance photometry, ${ }^{9}$ spectrofluorimetry, ${ }^{\mathbf{1 0}}$ HPLC with electrochemical detector, ${ }^{\mathbf{1 1}}$ aptasensors, ${ }^{\mathbf{1 2}}$ membrane sensors with rhodamine $\mathrm{B},{ }^{\mathbf{1 3 , 1 4}}$ molecularly-imprinted solid-phase extraction and adsorptive differential pulse voltammetry ${ }^{\mathbf{1 5}}$ and modifying an edge-plane pyrolytic graphite electrode with single-wall carbon nanotubes. ${ }^{\mathbf{1 6}}$

The mixture of DCF and ACT has been shown to decrease morphine consumption during heart surgeries and to reduce postoperative nausea and vomiting ${ }^{17}$ and to display greater efficiency than separate drugs, to relieve pain in cesarean patients. ${ }^{18}$ On the other hand, these drugs have been classified as emerging contaminants in both wastewater and drinking water, ${ }^{19,20}$ making imminent the development of affordable, simpler, analytical methods for their simultaneous determination.

In this work, a simple methodology based on the electrochemical oxidation of the DCF and ACT drugs will be shown for the first time, for individual and/or simultaneous quantification (as in mixtures) in aqueous solution, using a modified carbon paste electrode, CPE, with hemimicelles of the cationic surfactant cetyltrimethylammonium bromide (CTAB).

\section{Experimental}

All reactants were analytical grade; the drugs diclofenac and acetaminophen (Sigma) were purchased under the form of sodium salt and acid respectively, phosphate salts and sodium hydroxide (J. T. Baker) and CTAB (Aldrich). All solutions were 
prepared with deionized water from a Milli-Q (Millipore) instrument with $18.0 \mathrm{M} \Omega \mathrm{cm}$ resistivity. When DCF and ACT were mixed in real samples, they were made from Tempra ${ }^{\circledR}$ I.V., solution $500 \mathrm{mg}$ of acetaminophen $10 \mathrm{mg} \mathrm{mL}^{-1}$ (ACT) and AMSA ${ }^{\circledR}$ injectable $75 \mathrm{mg} / 3 \mathrm{~mL}$ (DCF). The synthetic urine was prepared according to Deroco et al. ${ }^{21}$ Thus, $0.73 \mathrm{~g}$ of $\mathrm{NaCl}, 0.40 \mathrm{~g}$ of $\mathrm{KCl}, 0.28 \mathrm{~g}$ of $\mathrm{CaCl}_{2} \cdot 2 \mathrm{H}_{2} \mathrm{O}, 0.56 \mathrm{~g}$ of $\mathrm{Na}_{2} \mathrm{SO}_{4}, 0.35 \mathrm{~g}$ of $\mathrm{KH}_{2} \mathrm{PO}_{4}$, $0.25 \mathrm{~g}$ of $\mathrm{NH}_{4} \mathrm{Cl}$, and $6.25 \mathrm{~g}$ of urea were placed in a $250 \mathrm{~mL}$ volumetric flask and the volume was completed with water. The samples thus prepared were used immediately after. Also, these samples were added with $33 \mu \mathrm{M}$ ACT (from Tempra®), 22.7 $\mu \mathrm{M}$ DCF (from AMSA ${ }^{\circledR}$ ). The potentiometer was a pH/Ion Analyzer $(\mathrm{HACH})$ coupled to a glass electrode (HACH series $5010 \mathrm{~T})$ to carry out $\mathrm{pH}$ measurements in the $0-14$ range. Throughout the experiments, the drug solution in the cell was maintained under a nitrogen atmosphere, precluded from light at $25{ }^{\circ} \mathrm{C}$.

A Perkin Elmer lambda 20 spectrophotometer was used to obtain the UV-Vis spectra with $1 \mathrm{~cm}$ optical path length quartz cells.

A potentiostat Epsilon BASi was used to perform electrochemical studies, aided by a conventional three-electrode cell comprising a bare CPE (displaying a geometric area of $0.071 \mathrm{~cm}^{2}$ ) as the working electrode, a Pt wire auxiliary electrode (BASi MW-1032) and Ag/AgCl (BASi MF-2021) as the reference electrode, to which all potentials in this work are quoted. The CPE was prepared by mixing graphite powder (Johnson Matthey $1 \mathrm{~mm}, 99.9 \%$ ) and mineral oil (Nujol) from Sigma-Aldrich in a $1: 1 \mathrm{w} / \mathrm{w}$ ratio; the resulting mix was placed in a polyethylene tube (10 $\mathrm{cm}$ long and $3 \mathrm{~mm}$ in diameter) containing a piston; the tip of the tube was then placed on a flat surface and the piston was pressed to achieve the elimination of trapped air. Electric contact was attained soldering a Pt wire to an external $\mathrm{Cu}$ connector; further details can be found in Ramírez et al. ${ }^{22,23}$

\section{Results and discussion}

Fig. 1 shows a linear predominance zones diagram constructed following the methodology proposed by Rojas-Hernández et al. ${ }^{24-27}$ for DCF, Fig. 1a, and for ACT, Fig. 1b, using the respective $\mathrm{p} K_{\mathrm{a}}$ values. ${ }^{27-29}$ For $\mathrm{DCF}$ it is observed that at $\mathrm{pH}$ values less than 4.15 the neutral species predominates and at higher pHs the anionic species predominates, whereas for ACT at $\mathrm{pH}$ less than 9.50, the neutral species predominates and for higher $\mathrm{pH}$ the anionic species. From these diagrams, it is clear that at $\mathrm{pH} 7$ the predominant DCF species is anionic while for ACT it will be neutral. Since CTAB is a cationic surfactant, see Fig. 1c, in aqueous solution will be as ionic $\mathrm{CTA}^{+}$molecules when $\left[\mathrm{CTA}^{+}\right]$is less than the respective critical micelle concentration, CMC, though micelles $\left(\mathrm{CTA}^{+}\right) n$ will form when $\left[\mathrm{CTA}^{+}\right]>$ CMC.

\subsection{Spectrophotometric study of interaction of $\mathrm{DCF}^{-}$and HACT with CTA ${ }^{+}$}

3.1.1 CMC determination. The CMC determines the concentration $(c)$ region in which the surfactant molecules present in the solution tend to form micelles ( $c>\mathrm{CMC}$ ) or where
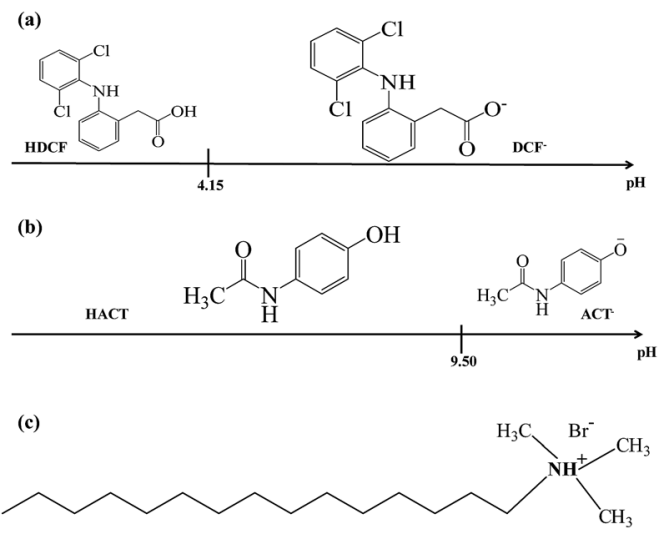

Fig. 1 Linear predominance zones diagram: (a) DCF and (b) ACT constructed following the methodology proposed Rojas-Hernández et al. ${ }^{24-27}$ (c) Cetyltrimethylammonium bromide's molecule.

they are mainly present as the monomer $(c<\mathrm{CMC})$. To determine CMC, UV-Vis absorption spectra of DCF were obtained by varying the concentration of $\mathrm{CTAB}$, see Fig. 2a. It can be observed that increasing CTAB concentration, the spectra displayed both bathochromic and hyperchromic effects. Fig. 2b shows the variation of absorbance recorded at $275 \mathrm{~nm}$, as a function of CTAB concentration, a slope change can be observed at $0.09 \mathrm{mM}$ CTAB concentration, corresponding to the
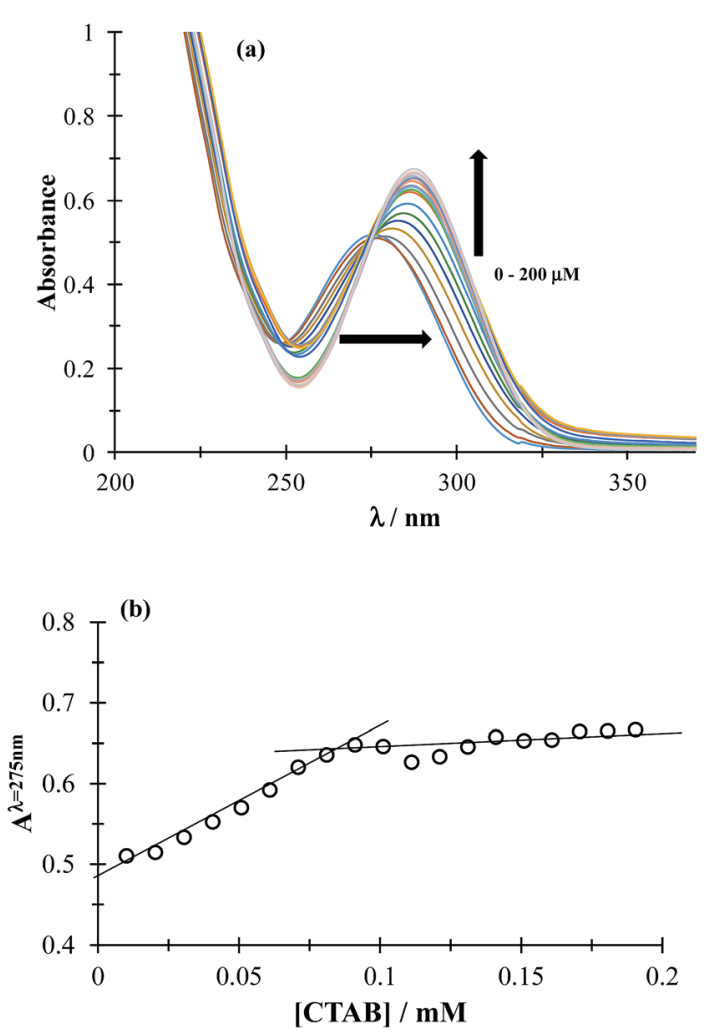

Fig. 2 (a) Family of UV-Vis spectra obtained in the $0.05 \mathrm{mM} \mathrm{DCF}$ system, in phosphate buffer at $\mathrm{pH} 70.1 \mathrm{M}$ for different CTAB concentrations shown in the figure. (b) Absorbance variation recorded at $275 \mathrm{~nm}$, as a function of CTAB concentration. 
CMC. It is important to stress that the CTAB CMC value may change with different factors, including the electrolyte nature and concentration, for instance Fuguet et al. ${ }^{30}$ found $(0.91 \pm$ $0.05) \mathrm{mM}$ and $(0.33 \pm 0.09) \mathrm{mM}$ in pure water and $5 \mathrm{mM}$ phosphate buffer ( $\mathrm{pH} 7.0)$ at $25{ }^{\circ} \mathrm{C}$, respectively while SánchezRivera et al. ${ }^{31}$ found a CMC value of $0.6 \mathrm{mM}$ in $0.1 \mathrm{M} \mathrm{NaCl}$ aqueous solution at $20^{\circ} \mathrm{C}$. Furthermore, we have also estimated the CMC value in the presence of both drugs and it was practically the same as that found when there was only DCF, which means that when CTAB concentration is higher than 0.09 it is in the form of micelles even in the presence of ACT.

Fig. 3 shows UV-Vis absorption spectra of $\mathrm{DCF}^{-}$molecules (Fig. 3a) and HACT (Fig. 3b) obtained in the presence and absence of CTAB for a $c>$ CMC. The spectrophotometric behavior of $\mathrm{DCF}^{-}$evidenced micelle formation $\left(\mathrm{CTA}^{+}\right) n$, whereas for the HACT, these micelles did not modify the behavior of their absorption spectrum.

\subsection{Electrochemical study of the $\mathrm{DCF}^{-}-\left(\mathrm{CTA}^{+}\right) n$ interaction}

Fig. 4 depicts linear sweep voltammograms (LSVs) obtained during the oxidation of $\mathrm{DCF}^{-}$in the presence and absence of CTAB. In the CTAB presence, the plot exhibits an anodic peak at $0.713 \mathrm{~V}$, while in its absence the anodic peak occurs at $0.630 \mathrm{~V}$. The presence of $\left(\mathrm{CTA}^{+}\right) n$ not only shifts the anodic peak $83 \mathrm{mV}$ towards more positive potentials but also increases the anodic
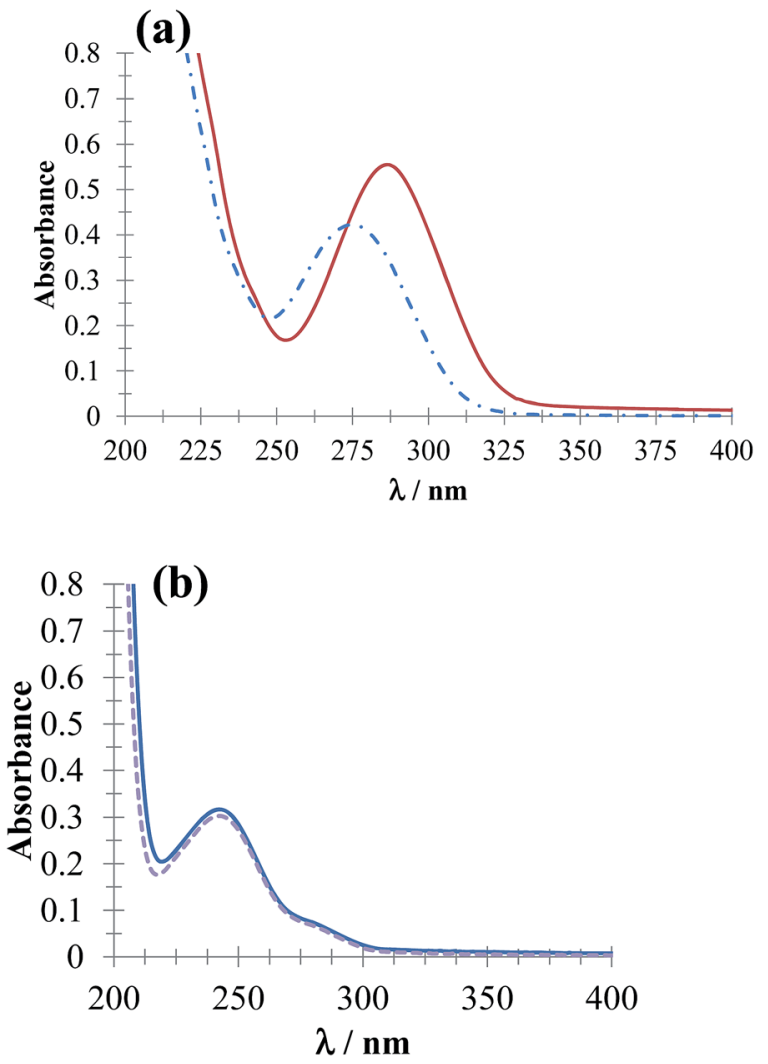

Fig. 3 UV-Vis absorption spectra obtained in the systems (a) $64 \mu \mathrm{M}$ DCF and (b) $64 \mu \mathrm{M} \mathrm{ACT}$ in phosphate buffer solution at $\mathrm{pH} 7.01$ in the presence of $0.1 \mathrm{mM} \mathrm{CTAB} \mathrm{(solid} \mathrm{line)} \mathrm{and} \mathrm{absence} \mathrm{(broken} \mathrm{line).}$

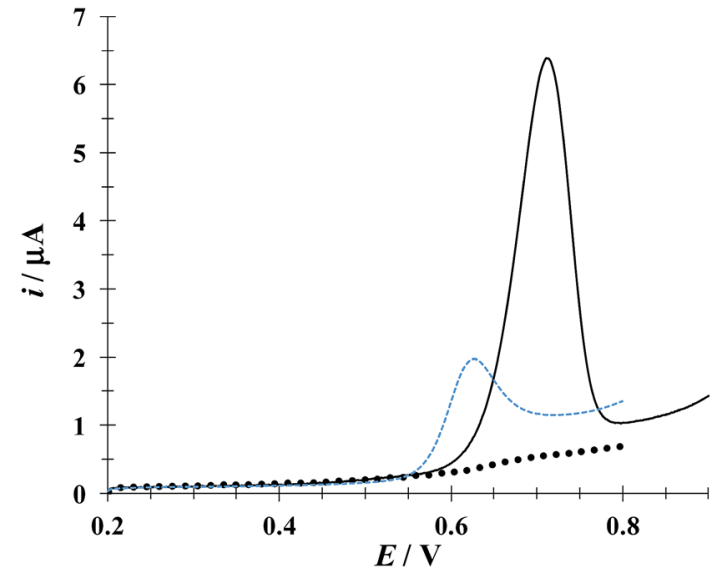

Fig. 4 Comparison of experimental LSVs recorded in the system CPE/ $16.34 \mu \mathrm{M} \mathrm{DCF}$, (phosphate buffer $0.1 \mathrm{M}, \mathrm{pH}$ 7) in the presence of $0.1 \mathrm{mM} \mathrm{CTAB}$ (solid line) and in the absence (broken line) The LSV of the system CPE/0.1 mM CTAB (solid circles) is also shown. In all cases the potential sweep started at $0.2 \mathrm{~V}$ at $100 \mathrm{mV} \mathrm{s}^{-1}$ rate.

peak current from 2 to $6.41 \mu \mathrm{A}$. This confirms the existence of a "supramolecular" interaction between the CTAB micelles and the DCF anionic form (see Fig. 1a). To deepen on this interaction, a study was performed considering different potential sweep speeds, see below.

Fig. 5 shows a LSVs family obtained during the electrochemical oxidation of $\mathrm{DCF}^{-}$applying different potential sweep speeds. It was found that the anodic peak current varies linearly with the sweep potential rate, see inset in Fig. 5. This indicates that this process is limited by the adsorption of $\mathrm{DCF}^{-}$on the surface of the electrode. ${ }^{30}$ Cid-Cerón et al. ${ }^{32}$ showed that in the absence of CTAB the electrochemical oxidation process of DCF on a CPE is limited by diffusion, therefore the $\mathrm{CTA}^{+}$hemimicelles formed on the surface of the $\mathrm{CPE}^{31}$ provoke the strong adsorption of $\mathrm{DCF}^{-}$, most probably through a supramoleculartype interaction, see Fig. 1a. This same effect has already been documented in the case of the electrochemical oxidation of dopamine in the presence of SDS by Corona-Avendaño et al. ${ }^{33}$

Considering the above features observed on the LSVs recorded at $[\mathrm{CTAB}]=0.1 \mathrm{mM}$, see Fig. 5 , and the case where the adsorbed species is electroactive, ${ }^{34-36}$ eqn (1) has been proposed to describe the experimental $i-E$ curves.

$$
i=\frac{n^{2} F^{2}}{R T} \frac{\nu A \Gamma_{\mathrm{O}}^{*}\left(b_{\mathrm{O}} / b_{\mathrm{R}}\right) \exp \left[(n F / R T)\left(E-E^{0^{\prime}}\right)\right]}{\left\{1+\left(b_{\mathrm{O}} / b_{\mathrm{R}}\right) \exp \left[(n F / R T)\left(E-E^{0^{\prime}}\right)\right]\right\}^{2}}
$$

where $A$ is the electrode surface area, $n$ is the number of electrons transferred during the heterogeneous reaction, $\nu$ is the potential scan rate, $R, T$ and $F$ are the universal gas constant, absolute temperature and Faraday constant, respectively. $E^{0^{\prime}}$ is the formal potential, $\Gamma_{\mathrm{O}}^{*}$ is the surface coverage, $b_{\mathrm{O}}$ and $b_{\mathrm{R}}$ are related to the adsorption free energy through eqn (2) and (3), respectively.

$$
\begin{aligned}
& b_{\mathrm{O}}=\exp \left(-\Delta G_{\mathrm{ads}, \mathrm{O}}^{0} / R T\right) \\
& b_{\mathrm{R}}=\exp \left(-\Delta G_{\mathrm{ads}, \mathrm{R}}^{0} / R T\right)
\end{aligned}
$$




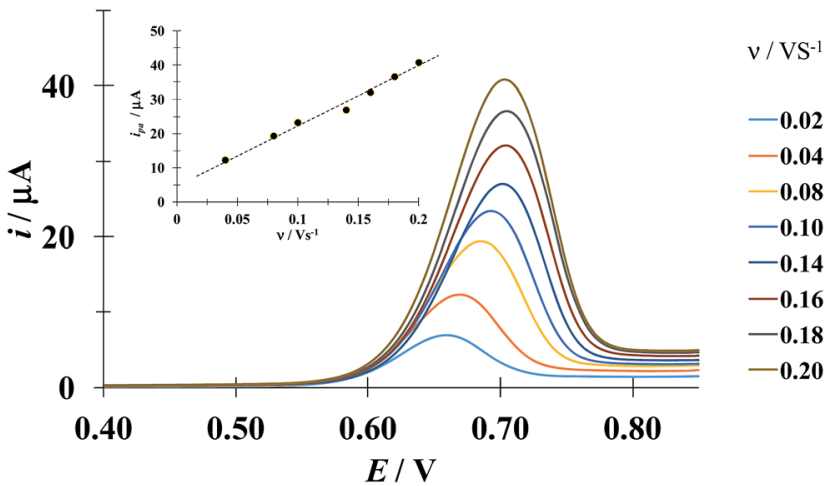

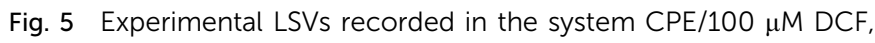
$0.1 \mathrm{mM}$ CTAB (phosphate buffer $0.1 \mathrm{M}, \mathrm{pH}$ 7). The potential sweep started at $0.4 \mathrm{~V}$ in the anodic direction for different rates indicated in the figure. The inset shows the anodic peak current $\left(i_{\text {pa }}\right)$ as a function of the potential sweep rate $(\nu)$. The broken line is the linear regression of the experimental data (solid circles).

The peak's potential and current are:

$$
\begin{gathered}
E_{\mathrm{p}}=E^{0^{\prime}}-\left(\frac{R T}{n F}\right) \ln \left(\frac{b_{\mathrm{O}}}{b_{\mathrm{R}}}\right) \\
i_{\mathrm{p}}=\frac{n^{2} F^{2}}{4 R T} \nu A \Gamma_{\mathrm{O}}^{*}
\end{gathered}
$$

Substituting eqn (4) and (5) in (1) yields eqn (6)

$$
i=\frac{4 i_{\mathrm{p}}\left(b_{\mathrm{O}} / b_{\mathrm{R}}\right) \exp \left[(n F / R T)\left(E-E^{0^{\prime}}\right)\right]}{\left\{1+\left(b_{\mathrm{O}} / b_{\mathrm{R}}\right) \exp \left[(n F / R T)\left(E-E^{0^{\prime}}\right)\right]\right\}^{2}}
$$

A parameterized form of eqn (6) is eqn (7)

$$
i=\frac{4 i_{\mathrm{p}} P_{1} \exp \left[(n F / R T)\left(E-P_{2}\right)\right]}{\left\{1+P_{1} \exp \left[(n F / R T)\left(E-P_{2}\right)\right]\right\}^{2}}
$$

where:

$$
\begin{aligned}
& P_{1}=\frac{b_{\mathrm{O}}}{b_{\mathrm{R}}} \\
& P_{2}=E^{0^{\prime}}
\end{aligned}
$$

Fig. 6 depicts a comparison of the experimental LSVs shown in Fig. 5 with their corresponding theoretical LSVs plots generated by non-linear fit of eqn (7) to the experimental data, the number of electrons for DCF $n=1$ was taken from CidCerón et $a l .{ }^{32}$ From this figure it can be concluded that the model on which eqn (1) is based, adequately described the experimental evidence and that when CTAB is present in the system, in concentrations greater that the $\mathrm{CMC}$, the reduced form of $\mathrm{DCF}^{-}$, is strongly adsorbed. For systems where strong adsorption of reactant and product are involved, the full peak's width at half-height (FWHM) should be equal to 90.6/ $n$ where $n$ is the number of electrons transferred during the electrochemical reaction. $n$ was calculated for each LSV using this characteristic and $n \approx 1$ was also obtained. The relatively small

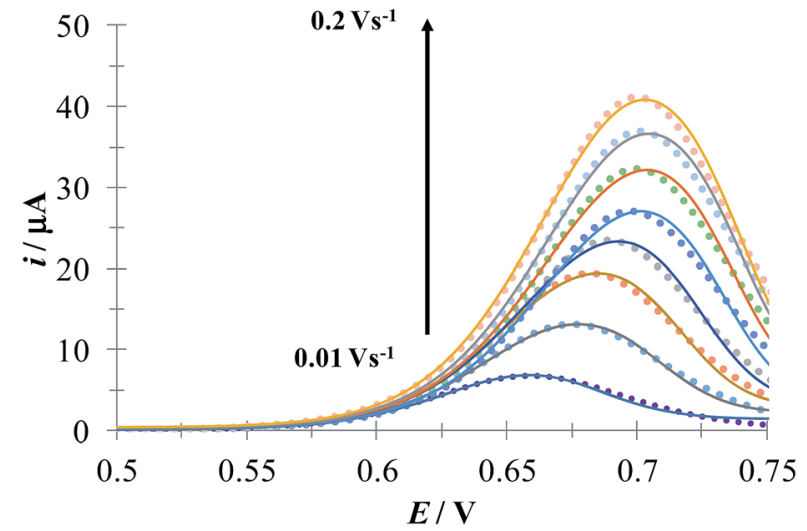

Fig. 6 Comparison of the experimental LSVs $(\bigcirc \bigcirc \bigcirc)$ reported in Fig. 5 and the theoretical LSVs (lines) generated by non-linear fit of eqn (7) to the experimental data. The best-fit parameters are reported in Table 1.

values for $P_{2}$ parameter suggest that the interaction between $\mathrm{CTAB}$ micelles and $\mathrm{DCF}^{-}$make the $\mathrm{DCF}^{-}$electrochemical oxidation a sluggish kinetic process.

\subsection{Electrochemical study of the HACT ${ }^{-}\left(\mathrm{CTA}^{+}\right) \boldsymbol{n}$ interaction}

Fig. 7 shows experimental LSVs recorded during the HACT oxidation in the presence and absence of CTAB. In both cases one anodic peak was obtained at $0.538 \mathrm{~V}$, however, the anodic peak current increases only by $1.23 \mu \mathrm{A}$ when the CTAB is present. Fig. S1, in the ESI, $\dagger$ shows the effect of the potential sweep rates on the HACT oxidation in the absence, Fig. S1a, $\dagger$ and in the presence, Fig. S1b, $\dagger$ of CTAB. In both cases the peak current varies linearly with $\nu^{1 / 2}$, see insets in Fig. S1a and S1b, $\dagger$ indicating that the process is limited by the diffusion of HACT. ${ }^{35}$ As shown in Section 3.1.1 in the case of HACT, CTAB also shows a smaller effect on their electrochemical properties compared to

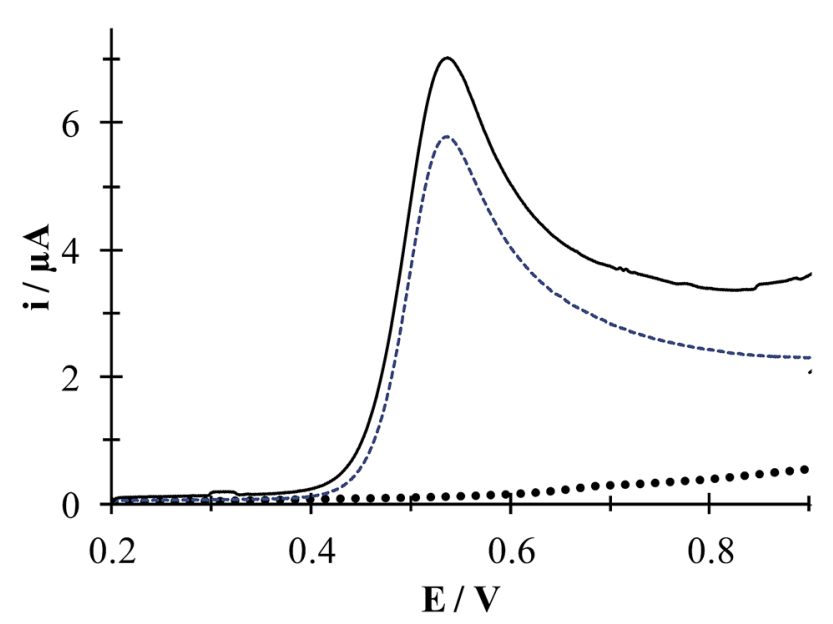

Fig. 7 Experimental LSVs recorded in system CPE/64.9 $\mu$ M ACT, (0.1 M phosphate buffer, $\mathrm{pH} 7$ ) in the presence (solid line) and the absence (broken line) of $0.1 \mathrm{mM} \mathrm{CTAB}$. The LSV of the system CPE/0.1 mM CTAB is shown by solid black circles. In all cases, the potential sweep started at $0.2 \mathrm{~V}$ at $100 \mathrm{mVs}^{-1}$ rate. 

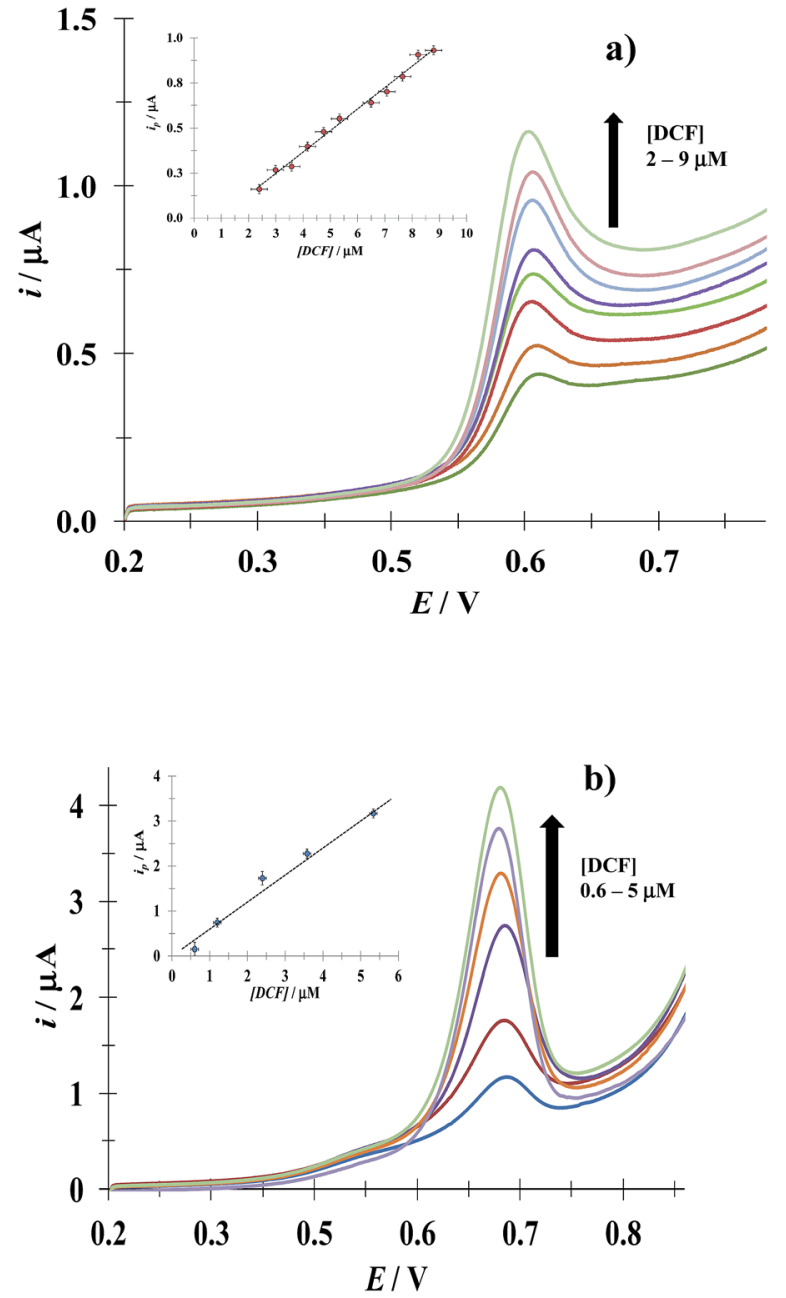

Fig. 8 Experimental LSVs recorded in the system CPE/(0.1 M phosphate buffer, $\mathrm{pH}$ 7) with different DCF concentrations (indicated in the figures) and two different CTAB concentrations: (a) 0 and (b) $0.1 \mathrm{mM}$. The potential scan rate started at $0.2 \mathrm{~V}$, in the positive direction at $100 \mathrm{mV} \mathrm{s}^{-1}$. The figures inset depict the variation of the respective anodic peak current $\left(i_{p}\right)$ as a function of the DCF concentration. The lines were obtained from the linear fit into the experimental data (solid circles).

$\mathrm{DCF}^{-}$, this is because unlike DCF, the ACT predominates in neutral form (see Fig. 1b) thus, its interaction with $\mathrm{CTA}^{+}$is negligible.

\subsection{Individual quantification of the drugs}

3.4.1 DCF. Fig. 8 shows LSVs recorded during the DCF electrochemical oxidation in the absence, Fig. 8a, and presence, Fig. $8 \mathrm{~b}$, of CTAB. In both cases, the respective anodic peak current $\left(i_{\mathrm{p}}\right)$ varies linearly with the DCF concentration; see the insets in Fig. 8. From these calibration plots it was possible to estimate the influence of CTAB on the analytical features, namely: the limits of detection (LOD) and quantification (LOQ) and the respective sensitivity as well, using the methodology reported by Swartz and Krull, ${ }^{37}$ see Table 2; it becomes plain that the CTAB presence improves the analytical features of the
Table 1 Best-fit parameters obtained by non-linear fit of eqn (7) to the LSVs recorded in the system CPE/DCF $100 \mu \mathrm{M}$, CTAB $0.1 \mathrm{mM}$ (phosphate buffer $0.1 \mathrm{M}, \mathrm{pH}$ 7), see Fig. 6

\begin{tabular}{lcc}
\hline$\nu / \mathrm{V} \mathrm{s}^{-1}$ & $10^{9} P_{1}$ & $P_{2} / \mathrm{V}$ \\
\hline 0.02 & 6.8 & 0.19 \\
0.04 & 16.0 & 0.22 \\
0.06 & 4.7 & 0.20 \\
0.08 & 12.0 & 0.24 \\
0.14 & 7.6 & 0.24 \\
0.16 & 11.0 & 0.24 \\
0.18 & 7.30 & 0.23 \\
0.2 & 22.0 & 0.25
\end{tabular}

Table 2 Analytical features depicted for the CPE toward DCF and ACT quantification as a function of [CTAB] recorded from the calibration plots shown as insets in Fig. 8 and S2 respectively

\begin{tabular}{llcccc}
\hline & {$[\mathrm{CTAB}] / \mathrm{mM}$} & Sensitivity $/ \mu \mathrm{A} \mu \mathrm{M}^{-1}$ & $\mathrm{LOD} / \mu \mathrm{M}$ & $\mathrm{LOQ} / \mu \mathrm{M}$ & $R^{2}$ \\
\hline DCF & 0 & $0.120 \pm 0.004$ & $0.70 \pm 0.30$ & $2.4 \pm 0.27$ & 0.998 \\
& 0.1 & $0.71 \pm 0.007$ & $0.73 \pm 0.30$ & $2.4 \pm 0.28$ & 0.999 \\
$\mathrm{ACT}$ & 0 & $0.085 \pm 0.001$ & $3.8 \pm 1.5$ & $12.8 \pm 1.4$ & 0.998 \\
& 0.1 & $0.11 \pm 0.01$ & $7.6 \pm 3.0$ & $25.4 \pm 2.7$ & 0.997 \\
& & & & &
\end{tabular}

electrode. Furthermore, as can be noted from Table 3, this rather simple electrode depicts similar or better analytical features towards DCF quantification as compared with other more sophisticated electrodes and/or techniques.

3.4.2 ACT. From the calibration plots obtained using the respective experimental LSVs, see Fig. S2 in the ESI $\dagger$ of this work, it was possible to evaluate the influence of CTAB on the analytical features of the CPE towards ACT quantification, see Table 2. Once again, the presence of CTAB improves the analytical features of the electrode. Moreover, as can be noted from Table 4, this simple electrode depicts similar or better analytical features towards ACT quantification as compared with other more sophisticated electrodes and/or techniques.

\subsection{Simultaneous quantification of DCF and ACT}

Fig. 9 shows a comparison of LSVs recorded during the electrochemical oxidation of HACT and $\mathrm{DCF}^{-}$, using a CPE, both present in the same aqueous solution at the same concentration, in the absence and presence of CTAB. Even when in the absence of CTAB two voltammetric peaks corresponding to HACT and $\mathrm{DCF}^{-}$could be distinguished with a $\Delta E_{\mathrm{p}}=E_{\mathrm{pDCF}}-$ $E_{\mathrm{pACT}}=630-525=105 \mathrm{mV}$, the presence of CTAB changed this potential difference to $158 \mathrm{mV}$, which is not a drastic change, however the current peak associated to $\mathrm{DCF}^{-}$went from 8.81 to $19.1 \mu \mathrm{A}(117 \%$ increase) while that corresponding to HACT solely depicted a slight increase from 7.52 to $8.35 \mu \mathrm{A}$. It is important to note that even when the CTAB alone showed some electrochemical activity in this potential region, it can be considered negligible (for instance, it is $0.76 \mu \mathrm{A}$ at the $E_{\mathrm{pDCF}}$ value in the presence of $\mathrm{CTAB}$ ). 
Table 3 Comparison of the analytical features towards DCF quantification reported for different experimental techniques $\mathrm{n}$. $\mathrm{r}$. $=$ not reported

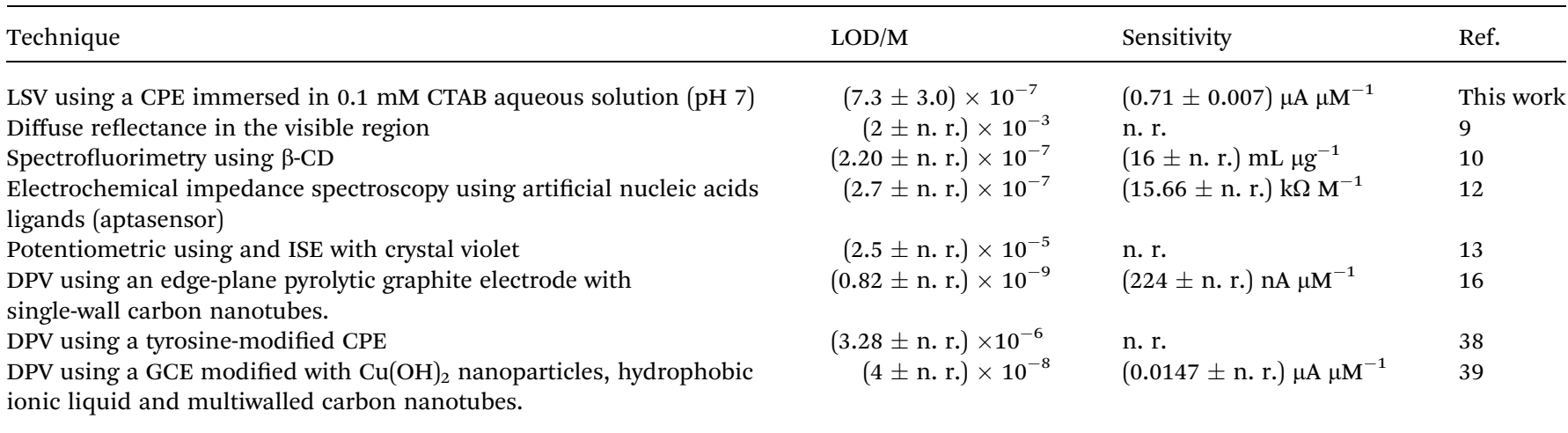

Table 4 Comparison of the analytical features towards ACT quantification reported for different experimental techniques ${ }^{a}$

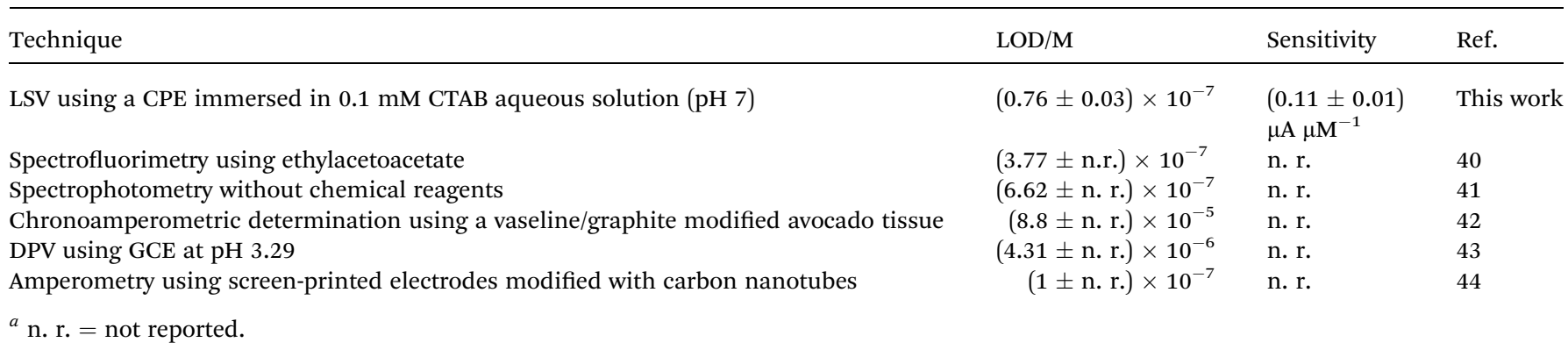

3.5.1 DCF quantification in the presence of a fixed [ACT]. Fig. 10 shows the LSVs recorded during $\mathrm{DCF}^{-}$electrochemical oxidation in the presence of fixed concentration of HACT and CTAB but varying the $\mathrm{DCF}^{-}$concentration. The calibration plot for $\mathrm{DCF}^{-}$quantification was obtained from this plot, see the inset in Fig. 10. The analytical parameter depicted for this electrode towards $\mathrm{DCF}^{-}$quantification in the presence of HACT

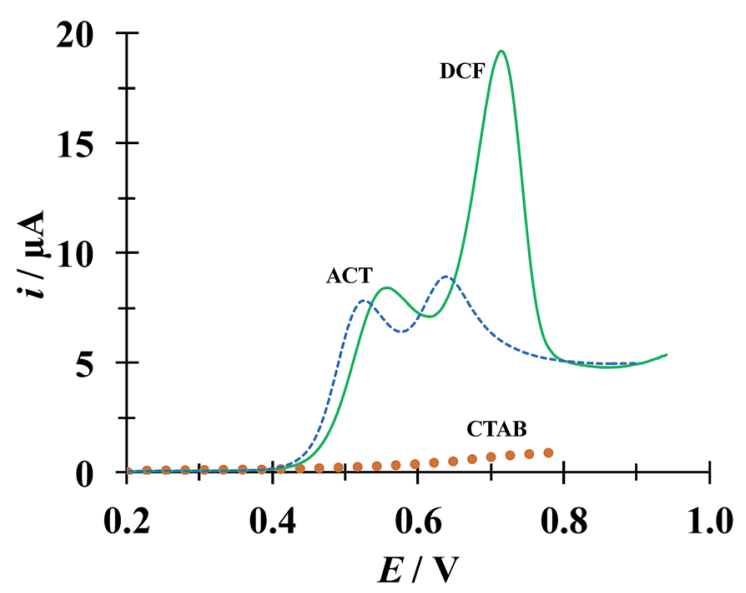

Fig. 9 Comparison of LSVs recorded in the systems: CPE/51.98 $\mu \mathrm{M}$ DCF, $51.98 \mu \mathrm{M} \mathrm{ACT}(0.1 \mathrm{M}$ phosphate buffer, $\mathrm{pH}$ 7) with different CTAB concentrations 0 (broken line) and $0.1 \mathrm{mM}$ (solid line). The LSV corresponding to the system $C P E / 0.1 \mathrm{mM} C T A B$ (solid circles) was also included. In all cases, the potential scan rate started at $0.2 \mathrm{~V}$, in the positive direction at $100 \mathrm{mV} \mathrm{s}^{-1}$. are reported in Table 5 along with those obtained in this same system but in the absence of CTAB, see Fig. S3. $\dagger$

3.5.2 ACT quantification in the presence of a fixed [DCF]. From the calibration plots obtained from the respective experimental LSVs, see Fig. S4 in the ESI $\dagger$ of this work, it was possible to evaluate the influence of CTAB on the analytical features of

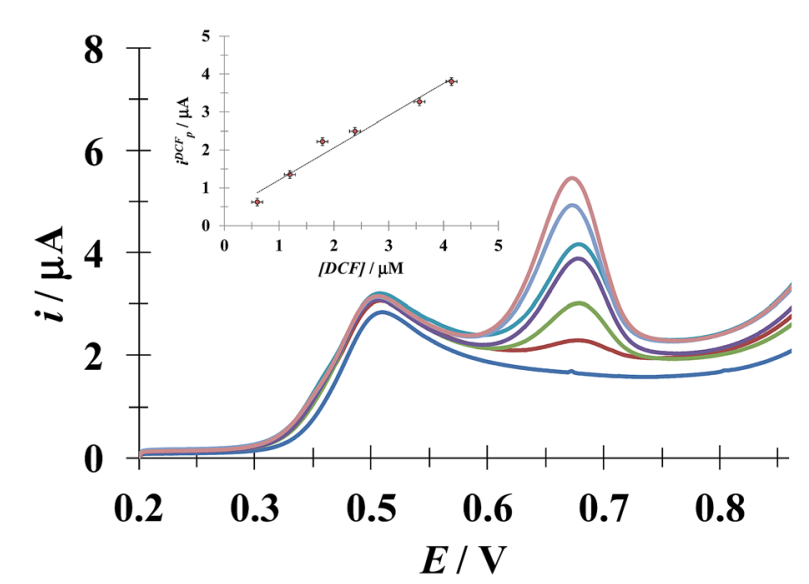

Fig. 10 Family of LSVs recorded in the systems: CPE/48.8 $\mu \mathrm{M} \mathrm{ACT,}$ $0.1 \mathrm{mM}$ CTAB (0.1 M phosphate buffer, $\mathrm{pH}$ 7) with different DCF concentrations indicated in the figure, in all cases the potential scan rate started at $0.2 \mathrm{~V}$, in the positive direction at $100 \mathrm{mV} \mathrm{s}^{-1}$. The insert depicts the variation of the DCF anodic current peak $\left(i_{\mathrm{pDCF}}\right)$ as a function of DCF concentration. The line was obtained from the linear fit into the experimental data (solid circles). 
Table 5 Analytical features depicted for the CPE toward DCF and ACT quantification, as a function of [CTAB] recorded from the calibration plots shown as insets in Fig. 10, S3 and S4 respectively

\begin{tabular}{|c|c|c|c|c|c|}
\hline & {$[\mathrm{CTAB}] / \mathrm{mM}$} & Sensitivity $/ \mu \mathrm{A} \mu \mathbf{M}^{-1}$ & $\mathrm{LOD} / \mu \mathrm{M}$ & $\mathrm{LOQ} / \mu \mathrm{M}$ & $R^{2}$ \\
\hline \multirow[t]{2}{*}{ DCF } & 0 & $0.10 \pm 0.013$ & $1.6 \pm 0.62$ & $5.6 \pm 0.67$ & 0.998 \\
\hline & 0.1 & $0.86 \pm 0.04$ & $0.50 \pm 0.21$ & $1.7 \pm 0.18$ & 0.997 \\
\hline & 0.1 & $0.054 \pm 0.001$ & $2.5 \pm 0.9$ & $8.3 \pm 0.98$ & 0.997 \\
\hline
\end{tabular}

the CPE towards ACT quantification in the presence of a fixed concentration of DCF, see Table 5. Once more it is possible to note that the presence of CTAB improves the analytical features of the electrode.

From Table 6 it is possible to note that the simultaneous electrochemical, LSV, quantification of DCF and ACT using a simple CPE immersed in an aqueous solution containing $\left(\mathrm{CTA}^{+}\right) n$ micelles displays similar or better analytical features towards ACT quantification as compared with other more sophisticated electrodes and/or techniques.

3.5.3 Quantification of DCF and ACT in real samples. ACT and DCF are usually marketed as a combined formulation with a fixed of $6: 1(\mathrm{w} / \mathrm{w}) \mathrm{ACT} / \mathrm{DCF}$ ratio, although other proportions are also available. ${ }^{46}$ Fig. 11 shows LSV recorded in a mix of the drugs Tempra ${ }^{\circledR}$ (ACT) and AMSA ${ }^{\circledR}$ (DCF) (synthetic urine) having ACT/DCF ratio of $6: 1(\mathrm{w} / \mathrm{w})$ in the absence (broken line) and presence (solid line) of CTAB micelles. It results clear that the presence of this surfactant resolves the voltammetry signal of both drugs.

The determination in real samples was carried out using the curve of standard addition from LSVs recorded in the system CPE/DCF (from AMSA ${ }^{\circledR}$ ) ACT (from Tempra ${ }^{\circledR}$ ). See Fig. 12.

In the determination of the drug of DCF from AMSA $®$ using the curve from the Fig. 12(a) it was obtained $(24.70 \pm 1.1) \mathrm{mg} \mathrm{mL}^{-1}$. In the case of ACT it was obtained $(10 \pm 1.1) \mathrm{mg} \mathrm{mL}^{-1}$ from the pharmaceutical sample Tempra®. These amounts are acceptable because the content of these drugs in the prescription of the vial are, namely, $75 \mathrm{mg}$ per $3 \mathrm{~mL}$ for DCF and $10 \mathrm{mg}$ per $1 \mathrm{~mL}$ for ACT. It is worthy to mention that the LOD reached through our methodology is in good agreement with physiological levels that could be found in patient's urine. ${ }^{52}$

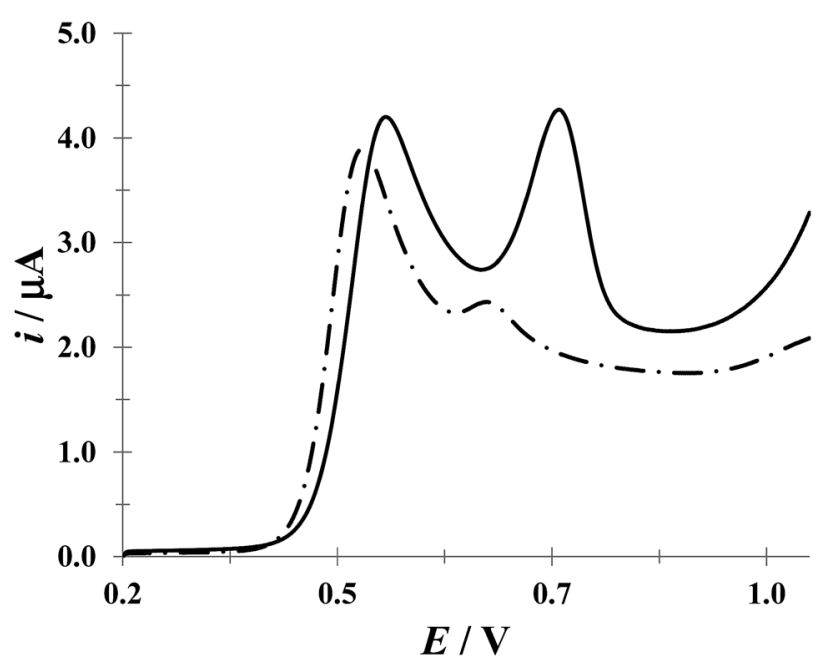

Fig. 11 Experimental LSVs recorded in the system CPE/39.3 $\mu \mathrm{M} \mathrm{ACT}$ (from Tempra ${ }^{\circledR}$ ), $3.11 \mu \mathrm{M}$ DCF (from AMSA ${ }^{\circledR}$ ) (synthetic urine, pH 5.3) with 0 (broken line) and $40 \mu \mathrm{M} \mathrm{CTAB}$ (solid line) in both cases the potential scan rate started at $0.0 \mathrm{~V}$, in the positive direction at $100 \mathrm{mV} \mathrm{s}^{-1}$.

Table 6 Comparison of the analytical features towards DCF quantification in the presence of ACT and its absence reported for different experimental techniques ${ }^{a}$

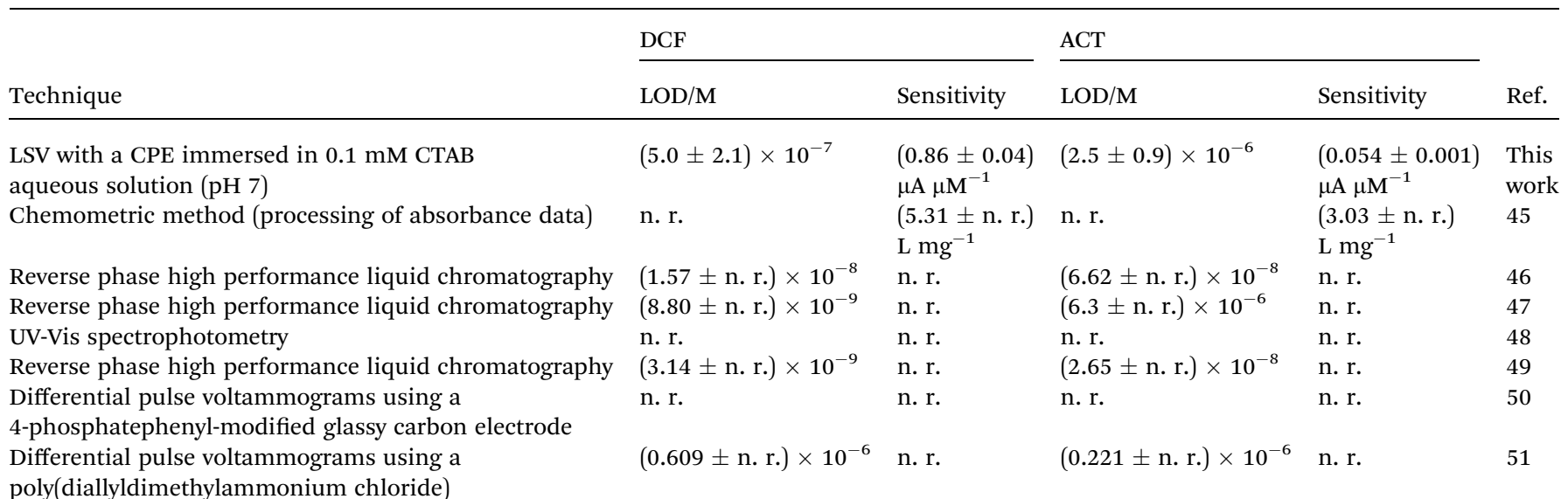
functionalized graphene

${ }^{a}$ n. r. $=$ not reported. 
a)

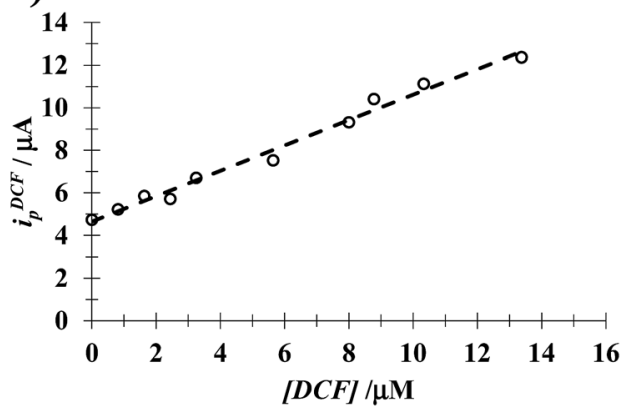

b)

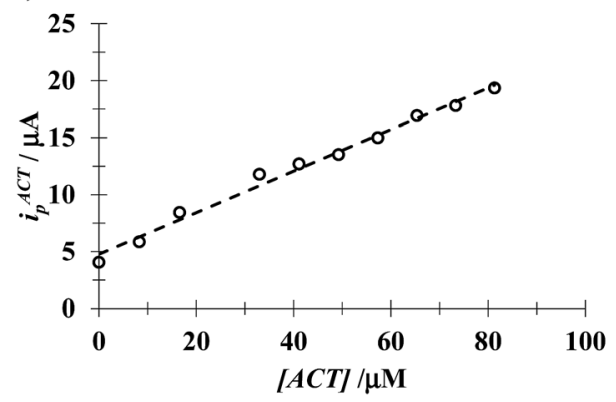

Fig. 12 Experimental curve of patron addition from LSVs recorded in the system CPE/DCF (from AMSA®) ACT (from Tempra ${ }^{\circledR}$ ) (synthetic urine). The additions were using standard of DCF and ACT respectively. The figure depicts variation of the anodic current peak $\left(i_{\mathrm{pDCF}}\right)$ as a function of DCF concentration (a) and variation of the anodic current peak ( $\left.i_{\mathrm{PACT}}\right)$ as a function of ACT concentration (b).

\section{Conclusions}

It was shown that CTAB hemimicelles, formed on the surfaces of a CPE, could be successfully used for the simultaneous electrochemical quantification of DCF and ACT dissolved in aqueous solution. The analytical performance, namely: LOD, LOQ and sensitivity, depicted by this inexpensive and rather simple manufacture, CTAB-modified CPE towards DCF and ACT quantification was evaluated, showing high selectivity and sensitivity even in real samples formed by commercial drugs and synthetic urine.

\section{Conflicts of interest}

There are no conflicts of interest to declare.

\section{Acknowledgements}

MMCC and MTRS thank CONACYT for support through project 237327 and DSGH and MTRS thanks CONACYT for cathedra 2159. MTRS, SCA, MEPH, MRR and MEPP like to thank SEP PRODEP for financial support through the RedNIQAE. DSGH, MTRS, SCA, MEPH, MRR and MPP wish to thank the SNI for the distinction of their membership and the stipend received.

\section{Notes and references}

1 M. J. Rosen and J. T. Kunjappu, Surfactants and Interfacial Phenomena, Wiley, 2012.

$2 \mathrm{~W}$. Liu and R. Guo, The interaction between morin and CTAB aggregates, J. Colloid Interface Sci., 2005, 290(2), 564-573.

3 S. Schreier, S. V. P. Malheiros and E. De Paula, Surface active drugs: Self-association and interaction with membranes and surfactants. Physicochemical and biological aspects, Biochim. Biophys. Acta, Biomembr., 2000, 1508(1-2), 210-234.

4 T. F. Tadros, Surfactants in Pharmaceutical Formulations. Applied Surfactants, Wiley-VCH Verlag GmbH \& Co. KGaA, 2005, pp. 433-501.

5 N. Vučinić-Milanković, S. Savić, G. Vuleta and S. Vučinić, Natural surfactant-based emulsion vehicles: A correlation between colloidal structure and in vitro release of diclofenac diethylamine, J. Dispersion Sci. Technol., 2010, 31(8), 1077-1084.

6 G. Alarcón-Angeles, S. Corona-Avendaño, M. Palomar-Pardavé, A. Rojas-Hernández, M. Romero-Romo and M. T. RamírezSilva, Selective electrochemical determination of dopamine in the presence of ascorbic acid using sodium dodecyl sulfate micelles as masking agent, Electrochim. Acta, 2008, 53(6), 3013-3020.

7 A. Arellano, S. Santoyo, C. Martn and P. Ygartua, Surfactant effects on the in vitro percutaneous absorption of diclofenac sodium, Eur. J. Drug Metab. Pharmacokinet., 1998, 23(2), 307-312.

8 P. L. Kole, J. Millership and J. C. McElnay, Determination of diclofenac from paediatric urine samples by stir bar sorptive extraction (SBSE)-HPLC-UV technique, Talanta, 2011, 85(4), 1948-1958.

9 M. Tubino and R. L. De Souza, Determination of diclofenac in pharmaceutical preparations by diffuse reflectance photometry, Talanta, 2006, 68(3), 776-780.

$10 \mathrm{~J}$. A. Arancibia and G. M. Escandar, Complexation study of diclofenac with $\beta$-cyclodextrin and spectrofluorimetric determination, Analyst, 1999, 124(12), 1833-1838.

11 A. Chmielewska, L. Konieczna, A. Plenis, M. Bieniecki and H. Lamparczyk, Determination of diclofenac in plasma by high-performance liquid chromatography with electrochemical detection, Biomed. Chromatogr., 2006, 20(1), 119-124.

12 L. Kashefi-Kheyrabadi and M. A. Mehrgardi, Design and construction of a label free aptasensor for electrochemical detection of sodium diclofenac, Biosens. Bioelectron., 2012, 33(1), 184-189.

13 Z. Kormosh, I. Hunka, Y. Bazel, N. Kormosh, A. Laganovsky and I. Mazurenko, A new diclofenac membrane sensor based on its ion associate with crystal violet. Application to diclofenac determination in urine and pharmaceuticals, $J$. Iran. Chem. Soc., 2007, 4(4), 408-413.

14 Z. Kormosh, I. Hunka, Y. Bazel, A. Laganovsky, I. Mazurenko and N. Kormosh, Determination of diclofenac in pharmaceuticals and urine samples using a membrane sensor based on the ion associate of diclofenac with Rhodamine B., Cent. Eur. J. Chem., 2007, 5(3), 813-823. 
15 L. Fernández-Llano, M. C. Blanco-López, M. J. LoboCastañón, A. J. Miranda-Ordieres and P. Tuñón-Blanco, Determination of diclofenac in urine samples by molecularly-imprinted solid-phase extraction and adsorptive differential pulse voltammetry, Electroanalysis, 2007, 19(15), 1555-1561.

16 R. N. Goyal, S. Chatterjee and A. R. S. Rana, The effect of modifying an edge-plane pyrolytic graphite electrode with single-wall carbon nanotubes on its use for sensing diclofenac, Carbon, 2010, 48(14), 4136-4144.

17 M. K. Fayaz, R. J. Abel, S. C. Pugh, J. E. Hall, G. Djaiani and J. S. Mecklenburgh, Opioid-sparing effects of diclofenac and paracetamol lead to improved outcomes after cardiac surgery, J. Cardiothorac. Vasc. Anesth., 2004, 18(6), 742-747.

18 B. Munishankar, P. Fettes, C. Moore and G. A. McLeod, A double-blind randomised controlled trial of paracetamol, diclofenac or the combination for pain relief after caesarean section, Int. J. Obstet. Anesth., 2008, 17(1), 9-14.

19 K. Fent, A. A. Weston and D. Caminada, Ecotoxicology of human pharmaceuticals, Aquat. Toxicol., 2006, 76(2), 122159.

20 B. Petrie, R. Barden and B. Kasprzyk-Hordern, A review on emerging contaminants in wastewaters and the environment: Current knowledge, understudied areas and recommendations for future monitoring, Water Res., 2014, 72, 3-27.

21 P. B. Deroco, F. C. Vicentini, G. G. Oliveira, R. C. Rocha-Filho and O. Fatibello-Filho, Square-wave voltammetric determination of hydroxychloroquine in pharmaceutical and synthetic urine samples using a cathodically pretreated boron-doped diamond electrode, J. Electroanal. Chem., 2014, 719, 19-23.

22 R. Martínez, M. T. Ramírez and I. González, Voltammetric Characterization of Carbon Paste Electrodes with a Nonconducting Binder. Part I: Evidence of the Influence of Electroactive Species Dissolution into the Paste on the Voltammetric Response, Electroanalysis, 1998, 10(5), 336342 .

23 M. T. Ramírez, M. E. Palomar, I. González and A. RojasHernández, Carbon paste electrodes with electrolytic binder: Influence of the preparation method, Electroanalysis, 1995, 7(2), 184-188.

24 A. Rojas-Hernández, M. T. Ramirez, J. G. Ibánez and I. Gonzalez, Construction of multicomponent pourbaix diagrams using generalized species, J. Electrochem. Soc., 1991, 138(2), 365-371.

25 A. Rojas-Hernández, M. T. Ramírez, J. G. Ibáñez and I. González, Relationship of multidimensional predominance-zone diagrams with multiconditional constants for complexation equilibria, Anal. Chim. Acta, 1991, 246(2), 435-442.

26 A. Rojas-Hernández, M. T. Ramírez, I. González and J. G. Ibáñez, Multi-dimensional predominance-zone diagrams for polynuclear chemical species, Anal. Chim. Acta, 1992, 259(1), 95-104.

27 A. Rojas-Hernández, M. T. Ramírez and I. González, Equilibria among condensed phases and a multi- component solution using the concept of generalized species. Part II. Systems with polynuclear species, Anal. Chim. Acta, 1993, 278(2), 335-347.

28 S. Babić, A. J. M. Horvat, D. Mutavdžić Pavlović and M. Kaštelan-Macan, Determination of pKa values of active pharmaceutical ingredients, TrAC, Trends Anal. Chem., 2007, 26(11), 1043-1061.

29 P. Norouzi, F. Dousty, M. R. Ganjali and P. Daneshgar, Dysprosium nanowire modified carbon paste electrode for the simultaneous determination of naproxen and paracetamol: Application in pharmaceutical formulation and biological fluid, Int. J. Electrochem. Sci., 2009, 4(10), 1373-1386.

30 E. Fuguet, C. Ràfols, M. Rosés and E. Bosch, Critical micelle concentration of surfactants in aqueous buffered and unbuffered systems, Anal. Chim. Acta, 2005, 548, 95-100.

31 A. E. Sánchez-Rivera, V. Vital-Vaquier, M. Romero-Romo, M. T. Ramírez-Silva and M. Palomar-Pardavé, Electrochemical deposition of cetyltrimethylammonium surface hemimicelles at the $\mathrm{Hg} / 0.1 \mathrm{M} \mathrm{NaCl}(\mathrm{aq})$ interface, $J$. Electrochem. Soc., 2004, 151(10), C666-C673.

32 M. M. Cid-Cerón, D. S. Guzmán-Hernández, M. T. RamírezSilva, A. Galano, M. Romero-Romo and M. PalomarPardavé, New insights on the kinetics and mechanism of the electrochemical oxidation of diclofenac in neutral aqueous medium, Electrochim. Acta, 2016, 199, 92-98.

33 S. Corona-Avendaño, G. Alarcón-Angeles, M. T. RamírezSilva, G. Rosquete-Pina, M. Romero-Romo and M. PalomarPardavé, On the electrochemistry of dopamine in aqueous solution. Part I: The role of [SDS] on the voltammetric behavior of dopamine on a carbon paste electrode, $J$. Electroanal. Chem., 2007, 609(1), 17-26.

34 E. Laviron, General Expression of the linear potential sweep voltammogram in the case of diffusionless electrochemical systems, J. Electroanal. Chem., 1979, 101, 19-28.

35 A. J. Bard and L. R. Faulkner, Electrochemical Methods: Fundamentals and Applications, Wiley, 2000.

36 M. Palomar-Pardavé, S. Corona-Avendaño, M. RomeroRomo, G. Alarcón-Angeles, A. Merkoçi and M. T. RamírezSilva, Supramolecular interaction of dopamine with $\beta$ cyclodextrin: An experimental and theoretical electrochemical study, J. Electroanal. Chem., 2014, 717-718, 103-109.

37 M. E. Swartz and I. S. Krull, Analytical Method Development and Validation, Marcel Dekker, New York, 1997, p. 92.

38 B. K. Chethana, S. Basavanna and Y. Arthoba Naik, Voltammetric determination of diclofenac sodium using tyrosine-modified carbon paste electrode, Ind. Eng. Chem. Res., 2012, 51(31), 10287-10295.

39 M. Arvand, T. M. Gholizadeh and M. A. Zanjanchi, MWCNTs/ $\mathrm{Cu}(\mathrm{OH}) 2$ nanoparticles/IL nanocomposite modified glassy carbon electrode as a voltammetric sensor for determination of the non-steroidal anti-inflammatory drug diclofenac, Mater. Sci. Eng., C, 2012, 32(6), 1682-1689.

40 A. De Los, M. Oliva, R. A. Olsina and A. N. Masi, Selective spectrofluorimetric method for paracetamol determination 
through coumarinic compound formation, Talanta, 2005, 66(1), 229-235.

41 K. A. R. Sirajuddin, A. Shah, M. I. Bhanger, A. Niaz and S. Mahesar, Simpler spectrophotometric assay of paracetamol in tablets and urine samples, Spectrochim. Acta, Part A, 2007, 68(3), 747-751.

42 O. Fatibello-Filho, K. O. Lupetti and I. C. Vieira, Chronoamperometric determination of paracetamol using an avocado tissue (Persea americana) biosensor, Talanta, 2001, 55(4), 685-692.

43 I. Baranowska and M. Koper, The preliminary studies of electrochemical behavior of paracetamol and its metabolites on glassy carbon electrode by voltammetric methods, Electroanalysis, 2009, 21(10), 1194-1199.

44 P. Fanjul-Bolado, P. J. Lamas-Ardisana, D. Hernández-Santos and A. Costa-García, Electrochemical study and flow injection analysis of paracetamol in pharmaceutical formulations based on screen-printed electrodes and carbon nanotubes, Anal. Chim. Acta, 2009, 638(2), 133-138.

45 P. M. Castellano, S. E. Vignaduzzo, R. M. Maggio and T. S. Kaufman, Application of a chemometric method for simultaneous determination of acetaminophen and diclofenac in content-uniformity and drug-dissolution studies, Anal. Bioanal. Chem., 2005, 382(7), 1711-1714.

46 B. Gowramma, S. Rajan, S. Muralidharan, S. N. Meyyanathan and B. Suresh, A validated RP-HPLC method for simultaneous estimation of paracetamol and diclofenac potassium in pharmaceutical formulation, Int. J. PharmTech Res., 2010, 2(1), 676-680.
47 K. Jana, L. Adhikari, S. K. Moitra and A. Behera, Analysis of multicomponent drug formulations (Diclofenac and paracetamol), Asian J. Pharm. Clin. Res., 2011, 4(2), 41-43.

48 S. Beeravolu, R. K. Vejendla and S. K. Nagula, Estimation and validation of UV-visible spectrophotometric method for combined tablet dosage form of paracetamol and diclofenac sodium using extraction technique, Int. J. Pharm. Technol., 2012, 4(3), 4733-4740.

49 S. N. Nag, B. Gouthami, L. Madhuri, N. Krishnaveni, S. N. Meyyanathan and B. Suresh, Development and validation of a RP-HPLC method for the simultaneous determination of paracetamol and diclofenac potassium on stainless steel surface of pharmaceutical manufacturing equipments, J. Chem. Pharm. Res., 2012, 4(3), 1670-1675.

50 T. Zhou, L. Li, J. Wang, X. Chen, G. Yang and Y. Shan, 4Phosphatephenyl-modified glassy carbon electrode for realtime and simultaneous electrochemical monitoring of paracetamol and diclofenac release from electrospun nanofibers, Anal. Methods, 2015, 7(21), 9289-9294.

51 O. K. Okoth, K. Yan, L. Liu and J. Zhang, Simultaneous Electrochemical Determination of Paracetamol and Diclofenac Based on Poly(diallyldimethylammonium chloride) Functionalized Graphene, Electroanalysis, 2016, 28(1), 76-82.

52 L. Fernández-Llano, M. C. Blanco-López, M. J. LoboCastañón, A. J. Miranda-Ordieres and P. Tuñón-Blanco, Determination of Diclofenac in Urine Samples by Molecularly-Imprinted Solid-Phase Extraction and Adsorptive Differential Pulse Voltammetry, Electroanalysis, 2007, 19(15), 1555-1561. 